\title{
Structural, Optical and Photocatalytic Properties of Co-Tio 2 Prepared by Sol-Gel Technique
}

\author{
Fatemeh Mostaghni ${ }^{a *}$, Yasaman Abed ${ }^{b}$ \\ ${ }^{a}$ Chemistry Department, Payam Noor University, P.O.Box: 19395-4697, Iran \\ ${ }^{b}$ Physic Department, Payam Noor University, P.O.Box: 19395-4697, Iran
}

Received: March 3, 2016; Accepted: April 26, 2016

\begin{abstract}
In the present work, the $\mathrm{Co} / \mathrm{TiO}_{2}$ nanocomposite was prepared by sol-gel method. The structural and optical properties of nanocomposite were studied using, X-ray diffraction (XRD) and diffuse reflectance UV-VIS spectrometry. The XRD spectra revealed its tetrahedral anatase structure. The grain size and optical properties of composite are also reported. Syntesied $\mathrm{Co} / \mathrm{TiO}_{2}$ photocatalyst showed excellent activity for the photodegradation of Methyl orange whether under visible and ultraviolet light irradiation.
\end{abstract}

Keywords: Anatase titania, Methyl orange, Photo catalytic process, Semiconductor

\section{Introduction}

Air and water pollutants are becoming a serious environmental problems around the globe. Indeed, over the last decade, environmental pollution remediation became a national and global priority ${ }^{1}$. One promising technique for removing contaminants is the photo catalytic degradation process. Nowadays, photo catalytic degradation processes have been widely applied as techniques for removing organic pollutants in wastewater and effluents, especially the degradation of dyes ${ }^{2}$.

Titanium dioxide is among the most studied because of its unique electrical behavior. It is usually used in the form of nanoparticles in suspension for high catalytic surface area and activity.

$\mathrm{TiO}_{2}$ exists in three polymorphs: anatase, rutile, and brookite of which the first two are the most common. These phases are characterized with high refractive index, low absorption and low dispersion in visible and near-infrared spectral regions, high chemical and thermal stabilities ${ }^{3}$. Anatase is found to have a highest activity in most studies ${ }^{4}$. The anatase phase $\mathrm{TiO}_{2}$ has been employed the photo catalytic degradation processes only under the ultra violet (UV) light illumination due to its large band gap $(\sim 3.2 \mathrm{eV})$. UV light accounts for less than $5 \%$ of the solar spectrum, and much effort is being made to modify $\mathrm{TiO}_{2}$ to make it respond better to visible and solar light ${ }^{5}$. Doping of metal ions into $\mathrm{TiO}_{2}$ is one of the possible ways to shift their onset of response from the UV to the visible region and increase its photo catalytic properties ${ }^{6-13}$. Co-doped anatase, in particular, is the object of a very large number of publications and review papers $^{14-18}$. Amadelli et al. synthesized the cobalt-modified $\mathrm{TiO}_{2}$ by the incipient impregnation method, they found that the modified oxide presents a higher photoactivity both for illumination with UVvisible $(\lambda>360 \mathrm{~nm})$ and visible light $(\lambda$ $>420 \mathrm{~nm} ; \lambda>450 \mathrm{~nm})$, and that this enhancement depends on the amount of the added species and on the final thermal treatment in the preparation step ${ }^{19}$.

However, these applications need high purity titania with controlled particle size, definite phase composition

* e-mail: mostaghnif@yahoo.com and surface properties. Therefore, it is important to control the particle size, morphology, and crystalline phase of the $\mathrm{TiO}_{2}$ system.

The important goal of the current investigation is the assessment of the effect of cobalt addition on the photocatalytic activity of $\mathrm{TiO}_{2}$ in the degradation of model organic pollutants. We focus on the structural and optical analysis of Co-doped $\mathrm{TiO}_{2}(20 \%)$ composite prepared by sol-gel method to identify the single phase formation. We used XRD technique and $\mathrm{UV}$-Vis spectroscopy for this purpose. Then photo catalytic activity of $\mathrm{Co} / \mathrm{TiO}_{2}$ was investigated for irradiation with visible and UV light irradiation.

\section{Materials and methods}

\subsection{Preparation of $\mathrm{Co} / \mathrm{TiO}_{2}$}

$\mathrm{Co} / \mathrm{TiO}_{2}$ nanoparticles were prepared by sol gel method. In a typical reaction, titanium (IV) isopropoxide (TTIP) and cobalt nitrate with the molar ratios 4:1 were dissolved in glacial acetic acid. Deionized water was added to it for hydrolysis and polycondensation reaction. In addition, polyethylene glycol (average molecular weight: 4000, Qualigen) served as a surfactant for this reaction and poured into the above mixture. The molar ratio of composition of the transition metal doped $\mathrm{TiO}_{2}$ sol was 1:2:10:200 of TTIP: PEG: glacial acetic acid: $\mathrm{H}_{2} \mathrm{O}$. The mixture was stirred for $1 \mathrm{~h}$ at room temperature. The gel preparation process started when both solutions were mixed together under vigorous stirring. The gel was then dried at $60^{\circ} \mathrm{C}$ for $2 \mathrm{~h}$ and calcinated at 300 , 450 and $550{ }^{\circ} \mathrm{C}$ for $3 \mathrm{~h}$ respectively.

$\mathrm{X}$-ray diffraction (XRD) patterns in the $2 \theta$ angular range from $5^{\circ}$ to $60^{\circ}$ were obtained by a Bruker make Diffractometer using $\mathrm{Cu} \mathrm{K} \alpha$ X-rays of wavelength $(\lambda)=1.5406 \AA$.

\subsection{Photocatalytic activity test}

The photo catalytic activity of the catalyst was examined under irradiation of two black light (UV-A, $\lambda>420)$ or two $30 \mathrm{w}$ high-power mercury lamps at $254 \mathrm{~nm}$ (30 W, UV-C) which were placed above a batch photoreactor. To $100 \mathrm{~mL}$ 
methylorange solution (30 ppm), $0.1 \mathrm{~g}$ of photo catalyst was added and the mixture was stirred for $30 \mathrm{~min}$ to obtain better dispersion and adsorption performance prior to the degradation. The $\mathrm{pH}$ value of the MO solution was adjusted to 3 and then $1 \mathrm{~mL} \mathrm{H}_{2} \mathrm{O}_{2}$ was dropped in as the oxidant. Then solution was exposed the visible light or ultraviolet light irradiation, so that the solution was illuminated from the top. At degradation time intervals of $0.5,1,2$ and $3 \mathrm{~h}$, the remaining MO in the sample solution was determined using a UV-visible spectrophotometer at $477 \mathrm{~nm}$, which is the maximum absorbance wavelength of the MO solution.

\section{Results and discussion}

\subsection{X-Ray diffraction studies}

We have discussed the effect of cobalt doping on the physical characteristics of $\mathrm{TiO}_{2}$. Since the final treatment in the preparation of the photocatalysts is calcination, we also carried out a series of experiments aiming to determine the optimal calcination temperature. The X-ray diffraction patterns of the cobalt doped $\mathrm{TiO}_{2}$ nanoparticles calcinated in different temperatures are shown in figure 1.

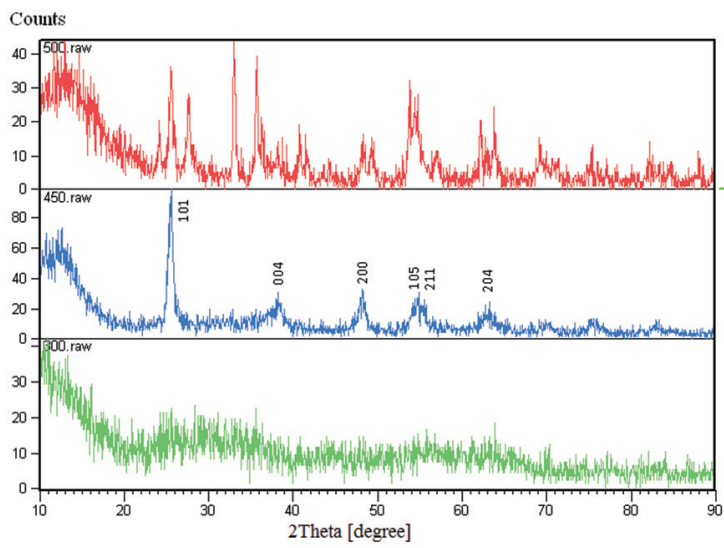

Figure 1: The X-ray diffraction patterns for the Co doped $\mathrm{TiO}_{2}$ treated at different temperature.

The samples characterization by X-ray diffraction Revealed, the sample treated up to $300{ }^{\circ} \mathrm{C}$ was exhibited amorphous behavior and the sample treated at $500^{\circ} \mathrm{C}$ showed some peaks characteristic of both rutile and anatase phases. Whereas the crystalline phase of treated sample in $450{ }^{\circ} \mathrm{C}$ was predominantly anatase with the absence of secondary or impurity peaks. This shows that the anatase phase is stable up to $450{ }^{\circ} \mathrm{C}$ and after that the rutile phase starts to grow. Peak details of the anatase $\mathrm{Co} / \mathrm{TiO}_{2}$ nanoparticles summarized in table 1.

Phase quantification was carried out using equation 1 and 2. This method is developed by and Myers ${ }^{20}$.

$$
X_{A} \%=\frac{100}{1+1.265 \frac{\mathrm{I}_{\mathrm{R}}}{\mathrm{I}_{\mathrm{A}}}}
$$

$$
X_{R} \%=\frac{100}{1+0.8 \frac{\mathrm{I}_{\mathrm{A}}}{\mathrm{I}_{\mathrm{R}}}}
$$

Here $X_{A}$ and $X_{R}$ are respectively the weight fractions of anatase and rutile $\left(\mathrm{X}_{\mathrm{R}}=1-\mathrm{X}_{\mathrm{A}}\right), \mathrm{I}_{\mathrm{A}}$ and $\mathrm{I}_{\mathrm{R}}$ are the intensity of the anatse (101) peak at $25.50^{\circ} 2 \theta$ and the rutile (110) peak at $27.56^{\circ} 2 \theta$ respectively. The weight fraction of rutile and anatase for the sample annealed at $500{ }^{\circ} \mathrm{C}$ have been 47.55 and 52.15 respectively.

The crystalline size of the particles in the anatase phase was calculated using the modified Debye-Scherrer equations from which a single value of $\mathrm{L}$ is obtained through all of the available peaks. The results indicate that nanocrystalline $\mathrm{Co} / \mathrm{TiO}_{2}$ powder with crystallite size of $11 \mathrm{~nm}$ have been successfully obtained.

\subsection{Optical absorption analysis}

The optical properties of the anatase $\mathrm{Co} / \mathrm{TiO}_{2}$ were characterized using UV-Vis diffuse reflectance spectroscopy. figure 2 represent $\mathrm{UV}$-Vis absorption spectrum of $\mathrm{Co} / \mathrm{TiO}_{2}$ nanoparticle.

The spectrum was taken in the range of 200-800 nm. The exciton absorption is at about $477 \mathrm{~nm}$. The band gap energy has been determined using the Tauc relation ${ }^{21}$, which is given by:

$$
(\alpha h v)^{n}=A\left(h v-E_{g}\right)
$$

where $\alpha$ is absorption coefficient, hv is energy of photon, Eg is optical band gap, A is a transition probability constant, and $\mathrm{n}$ is a simple fraction which relates to the optical absorption process. For indirect allowed, direct allowed, indirect forbidden, and direct forbidden transitions, $\mathrm{n}$ is equal to $1 / 2,2,1 / 3,2 / 3$ respectively.

Firstly, to establish the type of band-to-band transition which occur in the anatase $\mathrm{Co} / \mathrm{TiO}_{2}$ synthesized here, we have fitted the experimental absorption data to equation (3), for both indirect and direct band gap transitions using the exponent values $n=2$ and $n=1 / 2$ for the direct and indirect transitions, respectively.

Figure 3 shows the $(\alpha h v)^{1 / 2}$ versus $(h v)$ plot for an indirect transition and figure 4 shows the $(\alpha h v)^{2}$ versus $(h v)$ plot for a direct transition.

Extrapolating the linear part of the curves to the $\mathrm{X}$ axis yield the absorption energies, which correspond to the band gaps which are found to be 2.17 and $1.66 \mathrm{eV}$ for direct and indirect band gap respectively. The band gap values obtained for the direct and indirect transitions for pure and cobalt doped $\mathrm{TiO}_{2}$ are reported in table 2 .

The aim was to study whether cobalt doping causes the direct and indirect $\mathrm{TiO}_{2}$ band gap energy to change. Differences in the visible light absorption were foreseen as cobalt doping changes the color of the powders from white to dark green and causes a red shift in the absorption of light. As can be seen from the different $\mathrm{Eg}$ values, the indirect 
Table 1: Peak details of the anatase $\mathrm{Co} / \mathrm{TiO}_{2}$ nanoparticles.

\begin{tabular}{lcccccc}
\hline No. & 2Theta [deg.] & Height [cts] & FWHM $\theta[2]$. & d-spacing & Rel. Int. [\%] & Tip width [2 $\theta$.] \\
\hline 1 & 25.4678 & 78.44 & 0.5904 & 3.49752 & 100.00 & 0.6000 \\
2 & 38.2246 & 12.57 & 0.7872 & 2.35458 & 16.03 & 0.8000 \\
3 & 48.3163 & 14.56 & 0.5904 & 1.88375 & 18.57 & 0.6000 \\
4 & 1.09 & 1.3776 & 1.68693 & 1.39 & 1.4000 \\
5 & 54.3881 & 7.21 & 0.9600 & 1.47790 & 9.19 & 0.8000 \\
\hline
\end{tabular}

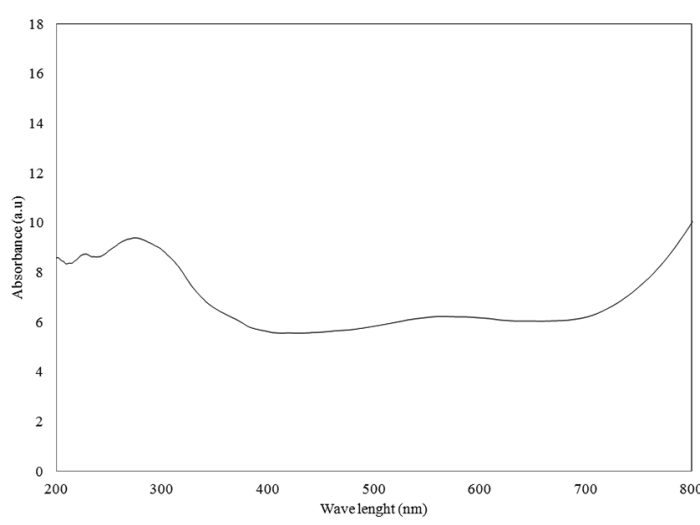

Figure 2: UV-Vis diffusion reflectance spectra of the $\mathrm{Co} / \mathrm{TiO}_{2}$.

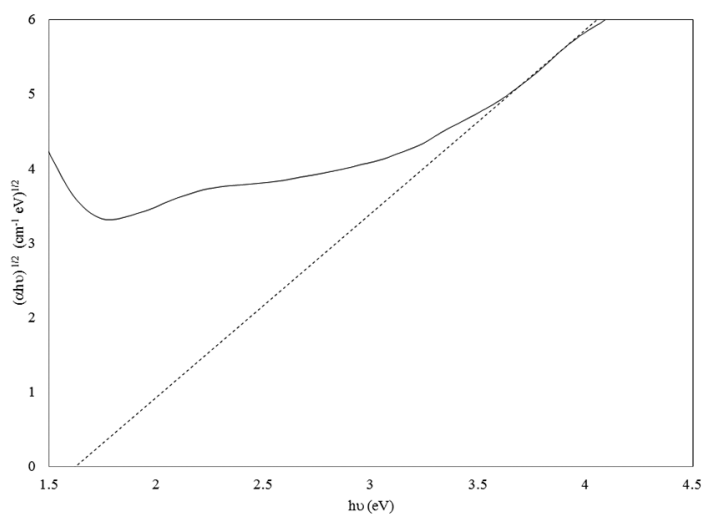

Figure 3: UV-vis diffuse reflectance spectra and plot $(\alpha h v)^{1 / 2}$ vs. photon energy (inset).

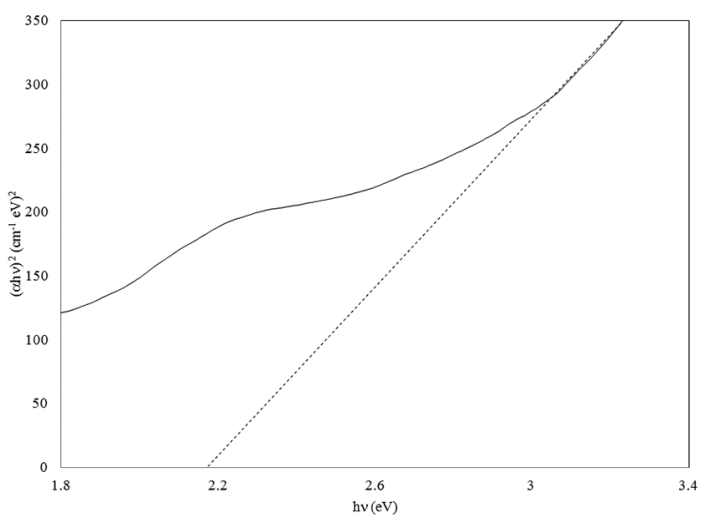

Figure 4: UV-vis diffuse reflectance spectra and plot $(\alpha h v)^{2}$ vs. photon energy (inset).
Table 2: The direct and indirect band gap values for pure and cobalt doped $\mathrm{TiO}_{2}$.

\begin{tabular}{lcc}
\hline \multirow{2}{*}{ Sample } & \multicolumn{2}{c}{ Band Gap (eV) } \\
& direct & indirect \\
\hline $\mathrm{TiO}_{2}$ & 3.25 & 3.08 \\
$\mathrm{Co} / \mathrm{TiO}_{2}$ & 2.17 & 1.64 \\
\hline
\end{tabular}

band gap is smaller than direct band gap. Moreover the band gap shifts estimated for the synthesized nanoparticles for indirect transition are larger than direct and therefore it could be inferred that the indirect transition is more appropriate.

\subsection{Photocatalytic activity}

The mechanism of photocatalysed reactions using the semiconductor compound could be described briefly as follows ${ }^{22}$. Firstly, the semiconductor compound absorbed photons, resulting in the generation of electron-hole pairs, known as excitons.

And the subsequent formation of adsorbed reactive species occurs through the diffusion of the valance band holes and the conduction band electrons to the surface of the semiconductor particles. In this reaction, $\mathrm{e}^{-}$and $\mathrm{h}^{+}$are powerful reducing and oxidizing agents, respectively. At the same time, the active sites of the surface of the semiconductor particles had been adsorbing a lot of pollutants particles, finally the decomposition of pollutants would be performed by charge carriers.

Addition of $\mathrm{H}_{2} \mathrm{O}_{2}$ as external oxidant/electron acceptor in photo catalytic process has been shown to improve the photo catalytic degradation of organic pollutants by ${ }^{23}$ :

1. Removing the electron-hole recombination by accepting the conduction band electron

2. Increasing the hydroxyl radical concentration and oxidation rate of intermediate compounds

3. Generating more radicals and other oxidizing species to accelerate the degradation efficiency of intermediate compounds.

In this section, we report on the influence of doping on the photoactivity of $\mathrm{Co}-\mathrm{TiO}_{2}$. Because of its environmental significance and non-biodegradation, methyl orange was selected as a reliable model pollutant in photo catalytic activity investigation. The existence of an optimum hydrogen peroxide concentration is typical and well-known in photo catalytic oxidation. This optimum value was previously found to be $10 \mathrm{mM}$ for $\mathrm{MO}$ degradation ${ }^{24}$.

$\mathrm{PH}$ is another main factor influencing the rate of degradation of some organic compounds in the photo catalytic process. The photo degradation of $\mathrm{MO}$ at different $\mathrm{pH}$ from 4 to 10 
have been studied ${ }^{25,26}$, and the best results obtained in acidic solution, $(\mathrm{pH}=3)$.

The photo degradation of MO is carried out in the presence of $\mathrm{Co} / \mathrm{TiO}_{2}$ photo catalyst and $\mathrm{H}_{2} \mathrm{O}_{2}$ under UV irradiation at $\mathrm{pH}=3$. The results showed that the intensity of the characteristic peak of $\mathrm{MO}$ at $\lambda \max =477 \mathrm{~nm}$ decreased gradually and complete discoloration of dye was observed after $3 \mathrm{~h}$ under optimum conditions. This proves that photo catalytic degradation is a viable means of dye removal from wastewaters. At degradation time intervals of $0.5 \mathrm{~h}$, the remaining MO in the sample solution was determined using a UV-visible spectrophotometer at $477 \mathrm{~nm}$, which is the maximum absorbance wavelength of the MO solution at $\mathrm{pH}=3$.

In the first step, calibration curve was obtained using standard MO solutions with known concentrations. Consequently, the degradation efficiency of the photo catalytic process was evaluated by the degradation ratio (D) of $\mathrm{MO}$, which was calculated with the following formula:

$$
\mathrm{D}(\%)=\frac{C_{o}-C_{t}}{C_{o}} \times 100
$$

Where $\mathrm{D} \%$ was the degradation rate of $\mathrm{MO}, \mathrm{C}_{0}$ and $\mathrm{C}_{\mathrm{t}}$ denote the initial and the time-dependent concentration respectively.

As shown in figure $5, \mathrm{Co} / \mathrm{TiO}_{2}$ presented $47 \%$ degradation rate of $\mathrm{MO}$ under visible light irradiation. When the degradation reaction of MO was conducted under ultraviolet light irradiation, the photocatalytic efficiencies were extremely enhanced compared with those observed under visible light conditions. The results indicate that $\mathrm{Co} / \mathrm{TiO}_{2}$ exhibited the best efficiency for the degradation of MO under UV light irradiation, which the degradation ratio reached up to $99 \%$ after $3 \mathrm{~h}$ of irradiation. Whereas pure $\mathrm{TiO}_{2}$ in the same condition showed only $68 \%$ Degradation.

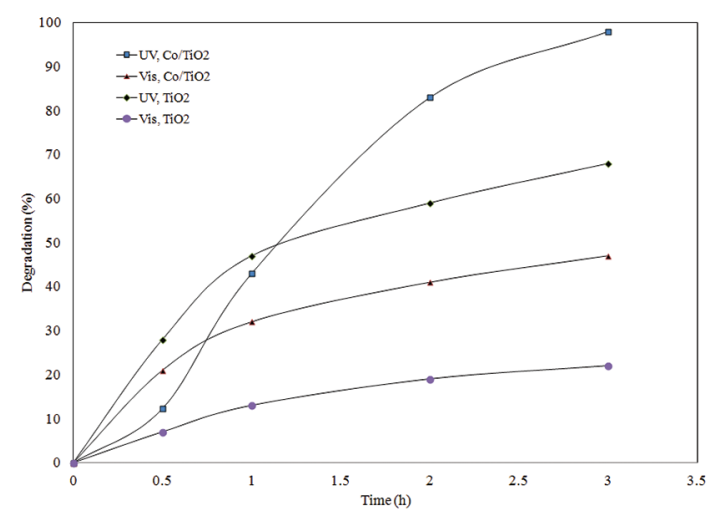

Figure 5: $\mathrm{Co} / \mathrm{TiO}_{2}$ photcatalyzed degradation of methyl orange.

\section{Acknowledgement}

We are thankful to the Payam Noor University for their support and encouragements.

\section{References}

1. Mezohegyi G, Gonçalves F, Órfão JJM, Fabregat A, Fortuny A, Font J, et al. Tailored activated carbons as catalysts in biodecolourisation of textile azo dyes. Applied Catalysis B: Environmental. 2010;94(1-2):179-185. DOI: http://dx.doi. org/10.1016/j.apcatb.2009.11.007

2. Zhang SJ, Yu HQ, Li QR. Radiolytic degradation of acid orange 7: a mechanistic study. Chemosphere. 2005;61(7):10031011. PMID: 15885740 DOI: http://dx.doi.org/10.1016/j. chemosphere.2005.03.008

3. Zallen R, Moret MP. The optical absorption edge of brookite $\mathrm{TiO}_{2}$. Solid State Communications. 2006;137(3):154-157. DOI: http://dx.doi.org/10.1016/j.ssc.2005.10.024

4. Wu MC, Sápi A, Avila A, Szabó M, Hiltunen J, Huuhtanen M, et al. Enhanced photocatalytic activity of $\mathrm{TiO}_{2}$ nanofibers and their flexible composite films: Decomposition of organic dyes and efficient $\mathrm{H} 2$ generation from ethanol-water mixtures. Nano Research. 2011;4(4):360-369. DOI: http://dx.doi.org/10.1007/ s12274-010-0090-9

5. Kumar SG, Devi LG. Review on modified $\mathrm{TiO}_{2}$ photocatalysis under UV/visible light: selected results and related mechanisms on interfacial charge carrier transfer dynamics. The Journal of Physical Chemistry A. 2011;115(46):13211-13241. DOI: http:// dx.doi.org/10.1021/jp204364a

6. Zaleska-Medynska A. Doped-TiO : a Review. Recent Patents on Engineering. 2008;2(3):157-164. DOI: http://dx.doi. org/10.2174/187221208786306289

7. Lee MS, Hong SS, Mohseni M. Synthesis of photocatalytic nanosized $\mathrm{TiO}_{2}-\mathrm{Ag}$ particles with sol-gel method using reduction agent. Journal of Molecular Catalysis A: Chemical. 2005;242(1-2):135-140. DOI: http://dx.doi.org/10.1016/j. molcata.2005.07.038

8. Mi JL, Johnsen S, Clausen C, Hald P, Lock N, Sø L, et al. Highly controlled crystallite size and crystallinity of pure and iron-doped anatase- $\mathrm{TiO}_{2}$ nanocrystals by continuous flow supercritical synthesis. Journal of Materials Research. 2013;28(3):333-339. DOI: http://dx.doi.org/10.1557/jmr.2012.234

9. Wu JCS, Chen CH. A Visible-light response vanadiumdoped titania nanocatalyst by sol-gel method. Journal of Photochemistry and Photobiology A: Chemistry. 2004;163(3):509-515. DOI: http:// dx.doi.org/10.1016/j.jphotochem.2004.02.007

10. Vu AT, Nguyen QT, Bui THL, Tran MC, Phuong DT, Tran TKH. Synthesis and characterization of $\mathrm{TiO}_{2}$ photocatalyst doped by transition metal ions $\left(\mathrm{Fe}^{3+}, \mathrm{Cr}^{3+}\right.$ and $\left.\mathrm{V}^{5+}\right)$. Advances in Natural Sciences: Nanoscience and Nanotechnology. 2010;1(1):015009.

11. Bouchet R, Weibel A, Knauth P, Mountjoy G, Chadwick AV. EXAFS Study of Dopant Segregation ( $\mathrm{Zn}, \mathrm{Nb})$ in Nanocrystalline Anatase ( $\mathrm{TiO}_{2}$ ). Chemistry of Materials. 2003;15(26):4996-5009. DOI: http://dx.doi.org/10.1021/cm034640n

12. You M, Kim TG, Sung YM. Synthesis of Cu-doped $\mathrm{TiO}_{2}$ nanorods with various aspect ratios and dopant concentrations. Crystal Growth \& Design. 2010;10(2):983-987. DOI: http://dx.doi. org/10.1021/cg9012944

13. Xin B, Wang P, Ding D, Liu J, Ren Z, Fu H. Effect of surface species on $\mathrm{Cu}-\mathrm{TiO}_{2}$ photocatalytic activity. Applied Surface Science. 2008;254(9):2569-2574. DOI: http://dx.doi.org/10.1016/j. apsusc.2007.09.002

14. Matsumoto Y, Murakami M, Shono T, Hasegawa T, Fukumura $\mathrm{T}$, Kawasaki M, et al. Room-temperature ferromagnetism in transparent transition metal-doped titanium dioxide. Science. 2001;291(5505):854-856. DOI: http://dx.doi.org/10.1126/ science. 1056186 
15. Prellier W, Fouchet A, Mercey B. Oxide-diluted magnetic semiconductors: a review of the experimental status. Journal of Physics: Condensed Matter. 2003;15(37):1583-1601. DOI: http://dx.doi.org/10.1088/0953-8984/15/37/R01

16. Geng WT, Kim KS. Interplay of local structure and magnetism in Co-doped $\mathrm{TiO}_{2}$ anatase. Solid State Communications. 2004;129(11):741-746. DOI: http://dx.doi.org/10.1016/j. ssc.2003.12.003

17. Bryan JD, Heald SM, Chambers SA, Gamelin DR. Strong room-temperature ferromagnetism in $\mathrm{Co}^{2+}$-doped $\mathrm{TiO}_{2}$ made from colloidal nanocrystals. Journal of the American Chemical Society. 2004;126(37):11640-11647. DOI: http:// dx.doi.org/10.1021/ja047381r

18. Coey JMD. Dilute magnetic oxides. Current Opinion in Solid State and Materials Science. 2006;10(2):83-92. DOI: http://dx.doi.org/10.1016/j.cossms.2006.12.002

19. Amadelli R, Samiolo L, Maldotti A, Molinari A, Valigi M, Gazzoli D. Preparation, Characterisation, and Photocatalytic Behaviour of $\mathrm{Co}^{-\mathrm{TiO}_{2}}$ with Visible Light Response. International Journal of Photoenergy. 2008;2008:[9p]. DOI: http://dx.doi.org/10.1155/2008/853753

20. Spurr RA, Myers H. Quantitative Analysis of AnataseRutile Mixtures with an X-Ray diffractometer. Analytical Chemistry. 1957;29(5):760-762. DOI: http://dx.doi. org/10.1021/ac60125a006
21. Bhatt R, Bhaumik I, Ganesamoorthy S, Karnal AK, Swami MK, Patel HS, et al. Urbach tail and bandgap analysis in near stoichiometric $\mathrm{LiNbO}_{3}$ crystals. Physica Status Solidi (A). 2014;6(4):17-22.

22. Paul T, Miller PL, Strathmann TJ. Visible-Light-Mediated $\mathrm{TiO}_{2}$ Photocatalysis of Fluoroquinolone Antibacterial Agents. Environmental Science \& Technology. 2007;41(13):4720-4727. DOI: http://dx.doi.org/10.1021/es070097q

23. Rasoulifard MH, Monfared HH, Masoudian S. Photo-assisted hetero-fenton decolorization of azo dye from contaminated water by $\mathrm{Fe}-\mathrm{Si}$ mixed oxide nanocomposite. Environmental Science \& Technology. 2011;32(13-14):1627-1635. DOI: http:// dx.doi.org/10.1080/09593330.2010.545996

24. Li Y, Zhang FS. Catalytic oxidation of Methyl Orange by an amorphous $\mathrm{FeOOH}$ catalyst developed from a high iron-containing fly ash. Chemical Engineering Journal. 2010;158(2):148-153. DOI: http://dx.doi.org/10.1016/j.cej.2009.12.021

25. Bao N, Feng X, Yang Z, Shen L, Lu X. Highly Efficient Liquid-Phase Photooxidation of an Azo Dye Methyl Orange over Novel Nanostructured Porous Titanate-Based Fiber of Self-Supported Radially Aligned $\mathrm{H}_{2} \mathrm{Ti}_{8} \mathrm{O}_{17} \cdot 1.5 \mathrm{H}_{2} \mathrm{O}$ Nanorods. Environmental Science and Technology. 2004;38(9):2729-2736. PMID: 15180072 DOI: http://dx.doi.org/10.1021/es034388k

26. Nam W, Kim J, Han G. Photocatalytic oxidation of methyl orange in a three-phase fluidized bed reactor. Chemosphere. 2002;47(9):10191024. DOI: http://dx.doi.org/10.1016/S0045-6535(01)00327-7 